\title{
REDES SOCIAIS: O CASO DOS CONFECCIONISTAS DO APL DE SANTA CRUZ DO CAPIBARIBE - PE ${ }^{1}$
}

\author{
SOCIAL NETWORKS: THE CASE OF MANUFACTURERS OF APL DE SANTA CRUZ DO \\ CAPIBARIBE-PE
}

\author{
Marcella Rachel Mignac de Barros Monteiro² \\ Helder Pontes Regis ${ }^{3}$ \\ Paulo Thiago Nunes Bezerra de Melo ${ }^{4}$
}

\begin{abstract}
RESUMO: Este estudo utilizou a abordagem estrutural do capital social para investigar os empresários participantes da associação dos confeccionistas. São apresentadas as ligações dos atores e da força dos laços existente entre eles na rede social. Foi utilizado um questionário como instrumento de pesquisa. A análise da rede se deu por meio do software UCINET 6.0 e NetDraw 2.1, que geraram como resultados os sociogramas de relacionamento. A população investigada dos confeccionistas associados foi de 25 indivíduos. Os resultados apontam para os diretores da instituição como os principais atores da rede, desempenhando um papel relevante para o desenvolvimento de ações empreendedoras no APL de confecções de Santa Cruz do Capibaribe. Os relacionamentos se mostram bem estruturados, com laços fortes bem concretizados dentro da rede. Destaca-se a necessidade do estabelecimento de laços com outros APLs da indústria de confecções com o intuito de se manterem fontes externas de informação.
\end{abstract}

PALAVRAS-CHAVE: Redes sociais, Capital Social, Arranjo Produtivo Local.

ABSTRACT: This study it used the structural boarding of the capital stock to investigate the participant entrepreneurs of the association of the ready-made clothiers. The linkings of the actors and the force of the bows existing between them in the social net are presented. A questionnaire was used as research instrument. The analysis of the net if gave by means of 6.0 software UCINET and NetDraw 2.1, that they had generated as resulted the sociogramas of relationship. The investigated population of the ready-made clothiers associates was of 25 individuals. The results point with respect to the directors of the institution as the main actors of the net, playing an excellent paper for the development of enterprising actions in the cluster of confections of Santa Cruz do Capibaribe. The relationships if show well structuralized, with well materialize strong bows inside of the net. It is distinguished necessity of the establishment of bows with other clusters of the industry of confections with the intention of if keeping external sources of information.

WORDKEYS: Social nets, Capital stock, Local Productive Arrangement.

\footnotetext{
${ }^{1}$ Artigo Recebido em 06.06.2010. Revisado por pares em 03.11.2010. Recomendado em 28.04.2011 por Leomar dos Santos Editor. Publicado em 28.07.2011.
}

Organização Responsável pelo periódico: Universidade regional de Blumenau - FURB - www.furb.br/rn

\footnotetext{
${ }^{2}$ Faculdade Boa Viagem - agcmachado@gmail.com

${ }^{3}$ Faculdade Boa Viagem - hregis@hotlink.com.br

${ }^{4}$ Faculdade Boa Viagem - pthiagoadm@hotmail.com
} 


\section{INTRODUÇÃO}

Os últimos anos vêm testemunhando uma profunda reestruturação das organizações, das regiões, da economia, do papel do governo e das pessoas. Os estudos mais recentes têm apresentado a introdução de novos paradigmas de gestão nas empresas, entre eles, a instalação de um grande número de firmas em espaços territoriais em que prevalece um ambiente favorável à atração de investimentos e ao desenvolvimento dos negócios (GALVÃO, 2000).

Os conceitos de clusters, distritos industriais e arranjos produtivos locais passaram a conviver com os modelos de análise para entender a mudança estrutural e o crescimento econômico das organizações. Da mesma forma, as relações sociais existentes em arranjos produtivos locais são capazes de facilitar a coordenação e o envolvimento dos agentes em ações cooperativas que levem a um desempenho econômico superior.

Os arranjos produtivos locais são aglomerados de empresas que apresentam especialização produtiva em uma mesma área, mantendo conexão de cooperação e aprendizagem entre si e com outros atores locais tais como governo, associações empresariais, instituições de crédito, ensino e pesquisa. Através do APL, as empresas contam com mais facilidade para a especialização produtiva e captação de investimentos. Clusters devem ser percebidos como sistema, em que há a interação de empresas de forma peculiar e específica, em que resulta numa notável capacidade de competir (ZACCARELLI et al, 2008).

Essa união de mercado é característica da Associação dos Confeccionistas da cidade de Santa Cruz do Capibaribe - PE (ASCAP), foco deste artigo. Santa Cruz do Capibaribe está localizada na mesorregião do agreste pernambucano, sendo considerada a terra da "sulanca". Além do comércio da sulanca, a cidade faz parte do Pólo de Confecção do Agreste, possuindo diversas fábricas e indústrias do ramo têxtil, realizando grandes importações e exportações. Estudos realizados pelo SEBRAE-PE (2003) na área do Pólo de Confecções apontam a existência de cerca de 12 mil unidades produtivas, e especificamente em Santa Cruz do Capibaribe, cerca de 8 mil unidades produtivas.

O êxito de um arranjo produtivo está relacionado a uma série de fatores que conectam as empresas umas às outras, aliada à flexibilidade e habilidade para atender a demanda. $\mathrm{O}$ relacionamento estabelecido entre as pessoas nessas ligações estimula a competitividade das empresas, a aprendizagem e auxiliam no acúmulo do capital social. Os compromissos sociais estabelecidos nessas interações sociais e que se manifestam nas redes de transação podem propiciar a disseminação de ações voltadas para a obtenção de uma eficiência coletiva.

As pessoas, dentro dessas organizações, fazem parte de redes de relacionamento que criam, modelam e limitam suas possibilidades de ação. Marteleto (2001) considera que as redes sociais ou networks são reproduções de um conjunto de participantes autônomos, unindo idéias e recursos em torno de valores e interesses partilhados. Explorar as informações originadas das redes sociais significa aceitar as relações de poder originárias de uma organização não-hierárquica e espontânea, procurando perceber até que ponto a dinâmica do conhecimento e da informação interfere nesse processo. Desta forma, a averiguação das redes sociais possibilita identificar os padrões de relacionamentos e suas mudanças através do tempo. A visualização das redes sociais no nível de comunidades e organizações permite 
analisar as redes locais pelo desenho das interações entre atores e as pessoas com mais influência (CLARK, 2006).

Neste artigo, a dimensão estrutural do capital social, na forma tridimensional apresentada por Régis, Dias e Bastos (2006), foi utilizada para a compreensão da formação da rede social informal que permeia o ambiente da associação dos confeccionistas de Santa Cruz do Capibaribe. Trata-se das ligações, sejam horizontais ou verticais, das posições dos atores e da força dos laços existente entre eles na rede social.

A ASCAP teve seu inicio em 1992, quando um grupo de confeccionistas reuniu-se com a finalidade de criar uma associação para defenderem os seus direitos e procurarem benefícios para a cidade. Inicialmente possuía 29 associados, possuindo hoje cerca de 175 associados, em sua maioria de empresas formalizadas. Algumas se formalizaram depois de comporem o quadro da ASCAP, uma vez que não há a exigência da empresa ser formalizada para fazer parte da associação. A missão da associação é representar os interesses dos confeccionistas locais e contribuir, através da prestação de serviços e parcerias, para o desenvolvimento sócio-econômico das empresas e do município.

\section{REDES SOCIAIS}

O estudo das redes de relações sociais é por si só, abrangente e complexo (RIGO; OLIVEIRA, 2007a). "As redes são sistemas compostos por "nós” e conexões entre eles que, nas ciências sociais, são representados por sujeitos sociais (indivíduos, grupos, organizações etc.) conectados por algum tipo de relação” (MARTELETO; SILVA, 2004, p. 41). Desta forma, a investigação das redes sociais possibilita identificar os padrões de relacionamentos e suas mudanças através do tempo.

As redes sociais podem ser vistas de maneiras distintas dentro das ciências sociais, podendo ser aplicada em diferentes situações e representam um conjunto de participantes independentes que através da união de idéias e recursos compartilham valores e interesses (MARTELETO, 2001). A teoria de rede social, ou rede de relacionamentos é uma teoria que constrói suas análises baseando-se nas relações dos indivíduos entre si e deles com as instituições sociais. As redes podem ser vistas como "a estrutura do campo no interior do qual estão imersos os atores sociais e políticos, relevantes em cada situação concreta” (MARQUES, 1999, p. 46). As relações sociais em que cada indivíduo está inserido podem ser vistas como uma rede. Cada pessoa pode ser vista pertencente a uma teia a partir da qual linhas conectam pessoas de seu convívio e relacionamento profissional (MARINHO-DASILVA, 2003).

Nos parágrafos a seguir serão abordados os principais conceitos que regem a análise das redes sociais. Desta forma, buscar-se-á compreender a conceituação básica a ser usada na análise da rede dos confeccionistas da ASCAP.

Apresenta-se inicialmente o conceito de ator, que pode ser um determinado indivíduo, um grupo ou unidades sociais coletivas. Podem-se exemplificar os atores com sendo as pessoas em um departamento dentro de uma empresa, pertencentes a um determinado grupo ou nações do mundo (WASSERMAN; FAUST, 1994). 
Cross e Prusak (2002) identificam quatro papéis desempenhados por atores das redes informais, a saber: os conectores centrais são atores bastante procurados, que ligam a maioria dos demais atores uns com os outros, possuindo conhecimento do local de trabalho e visão geral da atividade, podendo fornecer ou indicar soluções de problemas quando solicitado.

Os expansores de fronteira são aqueles atores que estão fora do centro da rede e que possuem bons contatos fora da organização. Assim, podem ser favoráveis na busca de soluções para questões que precisam de recursos e conhecimentos que a organização não tem, sendo necessário buscá-los em outra network.

Os corretores de informação são atores que conectam subgrupos da rede, evitando que o fluxo das informações seja interrompido através da fragmentação da rede. Os atores que desempenham o papel de corretor de informação são tão admiráveis quanto o conector central, pois possuem o mesmo poder sem possuir a quantia de ligações diretas que caracteriza este último. Por fim, os especialistas periféricos são atores a quem outros atores apelam quando necessitam de algum tipo de apoio especializado, de informações ou de conhecimento técnico ou de habilidades especificas (CROSS; PRUSAK, 2002).

Outro conceito dentro da análise das redes é o de ligações, que conectam um ator a outro, em que uma ligação mantida entre atores é um vínculo relacional.

Os Subgrupos são subconjuntos de atores, juntamente com todas as ligações entre eles. Subgrupos de dois atores e respectivas ligações recebem o nome de díades e subgrupos de três atores e respectivas ligações, tríades. "Um grupo consiste do conjunto finito de todos os atores entre os quais serão medidas as respectivas ligações existentes” (WASSERMAN; FAUST, 1994, p. 19). Ao agrupamento de ligações de um tipo específico entre os componentes de um grupo chama-se relação. Por exemplo, um conjunto de ligações de amizade entre os atores de um grupo ou o conjunto de ligações diplomáticas num grupo de nações são afinidades que definem uma relação (MARINHO-DA-SILVA, 2003). Uma rede social, destarte, consiste em um conjunto finito de atores e das relações estabelecidas entre eles.

Para se analisar as redes sociais, existem dois pontos de vista: por meio de suas características estruturais ou por meio de sua forma. A abordagem estrutural examina a estrutura da rede de maneira geral, através do levantamento de critérios estruturais, como densidade, tamanho, distâncias geodésicas e o diâmetro da rede social estudada. Centra-se ainda na análise sobre a coesão, os cliques e as equivalências estruturais (WASSERMAN; FAUST, 1994).

Na segunda abordagem, a análise deixa de ser feita especificamente sobre a rede social em geral e passa a focar determinados atores, na busca de encontrar o papel que estes desempenham dentro da rede, por meio do exame das medidas de centralidade (MARINHODA-SILVA, 2003).

O tamanho de uma rede é o total de ligações efetivas (relações reais) ou de ligações potenciais (relações latentes) existente num determinado grupo de pessoas, sendo este o mais importante critério estrutural da rede pessoal de um ator ou da rede social de um grupo, seja ela total ou parcial, uma vez que todos os demais critérios estruturais são calculados a partir do tamanho da rede (SCOTT, 2000). Na medida em que a população de atores cresce, a 
tendência é de cair a densidade de relações e pode ser que haja grupos de atores relacionandose.

A densidade de uma rede social é o quociente das ligações efetivamente existentes entre os atores da rede pelo total de ligações possíveis entre estes atores. A distância geodésica é definida como a passagem mais curta entre dois atores de uma rede. O diâmetro de uma rede é definido como a maior distância geodésica entre quaisquer pares de atores desta rede. Um dos objetivos mais importantes da análise de redes está relacionado ao levantamento de subgrupos coerentes dentro destas redes, ou seja, um subgrupo onde se supõe um grau de afinidade entre os atores para que as relações possam se estabelecer.

A centralidade de uma rede é definida como a medida do quão acessível um determinado ator está para os demais atores de uma rede. A centralidade é uma função não apenas do tamanho de uma rede, mas também de seu padrão de distribuição, ou o modo como os diversos atores estão interligados. Segundo Gómes et al (2003), é um recurso sociológico que não tem uma definição clara; é definido apenas de forma indireta. Um indivíduo pode ser considerado central em uma rede quando pode comunicar-se diretamente com muitos outros, ou está próximo de muitos atores ou, ainda, quando há muitos atores que o utilizam como mediador em suas comunicações.

A bibliografia existente sobre análise de redes sociais oferece possíveis medidas de centralidade, possuindo cada uma a mais perfeita indicação para determinado propósito. Podese destacar: as medidas de centralidade de grau, centralidade de proximidade, centralidade de intermediação e centralidade de Bonacich (MARINHO-DA-SILVA, 2003).

Considerando a centralidade de grau, esta é mensurada pelo número de ligações que um ator possui. “A centralidade de grau de entrada representa o número de ligações que um ator recebe de outros atores enquanto a centralidade de grau de saída representa o número de ligações que um determinado ator estabelece com outros atores de um grupo" (MARINHODA-SILVA, 2003). Nos estudos de análise de redes sociais, a centralidade de grau de saída avalia a expansividade de um ator e a centralidade de grau de entrada testa o seu prestígio (LAZEGA apud MARINHO-DA-SILVA, 2003) ou sua receptividade ou popularidade (WASSERMAN; FAUST, 1994).

O aspecto da centralidade de proximidade, diz Hanneman (2001), ressalta a distância de um ator em relação a outros, na rede. Este enfoque está baseado na distância geodésica de cada ator com todos os demais, considerando-se as distâncias tanto diretas quanto as indiretas. Isto é, quanto mais próximo um ator estiver de outros atores da rede, mais central ele estará.

A centralidade de intermediação, segundo Hanneman (2001), considera um ator como elemento central para alcançar outros atores, visto que ele está posicionado nos caminhos geodésicos entre outros pares de atores na rede. Marteleto (2001, p.79) afirma que um indivíduo pode ter escassos contatos diretos na rede, estar conectado necessariamente por ligações fracas, mas exercer um respeitável papel intermediando informações.

Por fim, a medida de centralidade de Bonacich, apresenta que o fato de um ator ser escolhido ou referenciado por outros atores de estima elevada não equivale a ser escolhido por atores marginais ou periféricos, ou seja, os prestígios individuais das ligações indiretas de um 
ator podem aumentar ou diminuir a medida de seu próprio prestígio (LAZEGA apud MARINHO-DA-SILVA, 2003).

\subsection{Capital Social}

Em trabalhos mais recentes, os sociólogos norte-americanos têm utilizado o conceito de capital social para corroborar a importância das redes na construção de relações sociais, nos quais tanto interesses pessoais como coletivos se imbricam. O conceito de capital social nasceu no campo dos estudos das redes sociais (RÉGIS, 2005).

De modo mais recente, o pensamento do capital social tem sido influenciado por James Coleman, escritor e sociologista americano da década de 80 e Robert Putnam, também Americano, escritor e cientista político da década de 90, bem como pelo filósofo Pierre Bourdieu. As idéias centrais destes autores podem ser visualizadas em poucas palavras conforme apresentado por Kay e Pearce (2003).

Coleman define a teoria social sobre capital social construída com base numa definição abrangente, estabelecendo que a proximidade ou conectividade de redes sociais podem produzir conexões mais próximas entre pessoas e que isto em si mesmo pode gerar obrigações e sanções na comunidade. "O conceito de capital social desenvolvido por James Coleman permite melhor compreender como se dão as relações de confiança, favoráveis à ação coletiva organizada, existentes entre os membros de um grupo de pessoas” (AQUINO, 2000, p.24).

Putnam é o principal representante da aplicação do conceito de capital social no âmbito de desenvolvimento regional (RIGO; OLIVEIRA, 2007b). Putnam reconheceu que "uma boa governança foi relacionada intensamente com engajamento cívico” e que uma coesão social em comunidade depende das redes sociais, e identificou normas de comportamento e confiança. Ele afirma que esses componentes "maquiam” o capital social em comunidades e que se faz necessário para melhorar a qualidade de vida e o desenvolvimento comunitário. Putnam (2000) apresenta a idéia dos dilemas da ação coletiva, em que certamente os problemas de determinada região poderiam ser "solucionadas" se todos cooperassem para o bem comum. Para ele, capital social refere-se às conexões sociais e as normas e confiança assistentes (PUTNAM, 2005).

Bourdieu mostrou como o capital social existe ao lado do capital econômico e cultural e pode ser parte de estratégias individuais e grupais para reproduzir mais capital social e ou converte-lo em outros formatos de capital.

Desta forma,

As diferentes abordagens do capital social conduzem a diferentes hipóteses. Mas existe consenso geral de que é "algo" que existe entre indivíduos e organizações. Este "algo" resulta de conexões (relações), e é desenvolvido através da crescente confiança, através da compreensão mútua e recíproca através de ações baseadas em normas e valores compartilhados (KAY; PEARCE, 2003, p. 03). 
O capital social está localizado não nos indivíduos, mas nas relações existentes entre eles, e a existência de capital social aumenta os recursos à disposição dos indivíduos que se encontram inseridos em tais relações (COLEMAN, 1990).

\subsection{Dimensões do Capital Social}

A forma como este estudo aborda o capital social toma como base as três dimensões do capital social empregadas por Nahapiet e Ghoshal (1998), são elas: a dimensão cognitiva, a dimensão estrutural e a dimensão relacional. Desta forma, Régis (2005), elaborou uma representação gráfica das três dimensões que são mostradas na Figura (1). Conforme Régis (2005), estas dimensões operam de forma concomitante para formar a complexidade das relações em rede.

A dimensão estrutural, mostrada na parte inferior da Figura (1), traz aspectos relacionados a força das relações e aspectos relacionados a configuração da network. A maioria dos estudos sobre redes sociais envolve esta dimensão do capital social, incluindo também os estudos sobre centralidade nas redes.

A dimensão cognitiva, apresentada na parte superior direita, explora os significados que são compartilhados pelos atores da rede. Estes podem ser conceitos comuns com relação a assuntos variados que fazem parte do contexto específico da rede e que orientam a tomada de decisões e os comportamentos.

Por fim, a dimensão relacional, mostrada na parte superior esquerda, aborda o conteúdo transacionado entre os atores da rede. Esta dimensão também considera os papéis que os atores assumem como: amigos, informantes ou confidentes. 


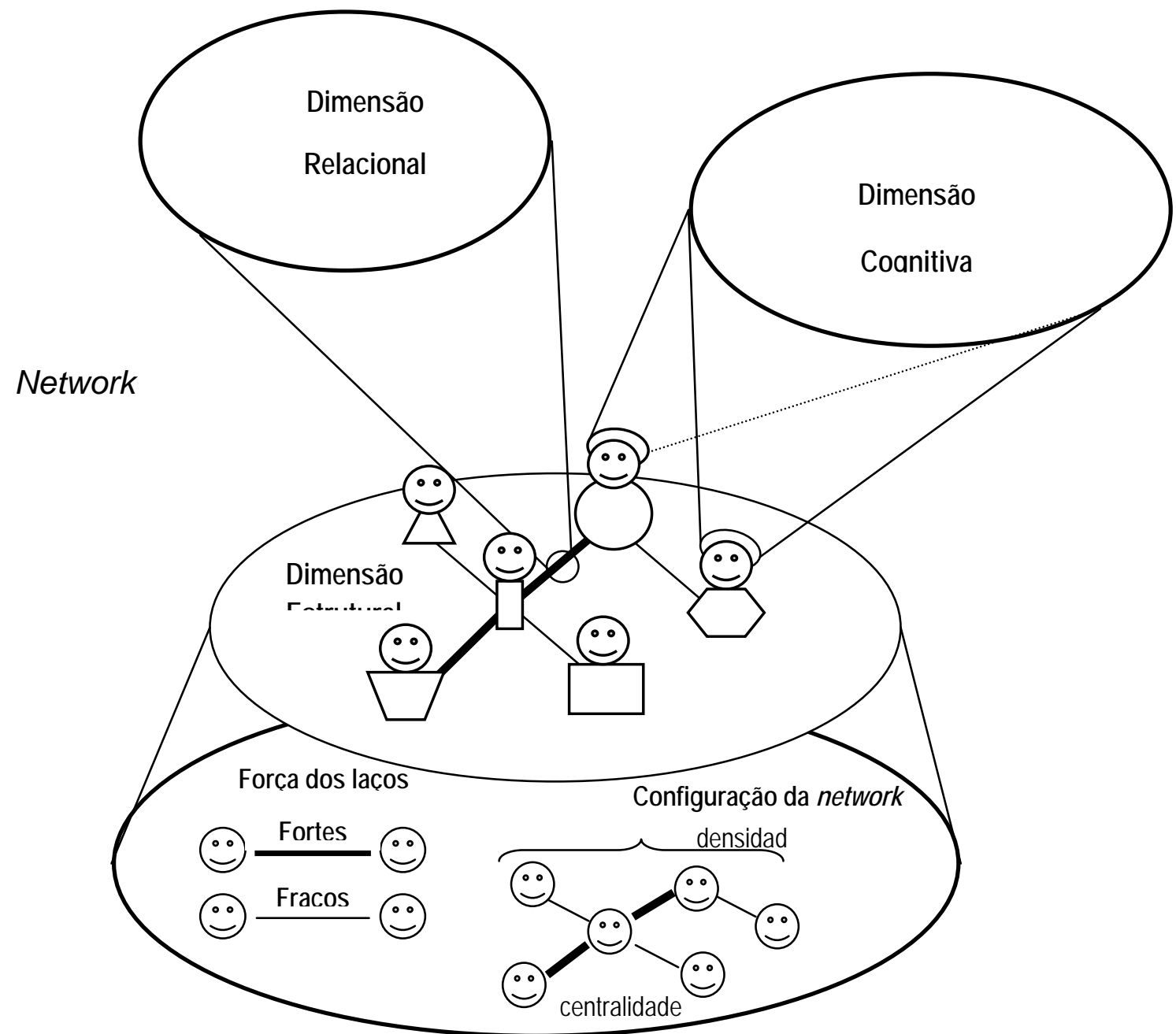

Figura 1: Dimensões do capital social

Fonte: Régis, 2005

Este estudo tem como foco a dimensão estrutural do capital social. Desta forma, é possível, através da dimensão estrutural, observar características marcantes como centralidade dos atores, força dos laços (laços fracos e fortes) e densidade. A dimensão estrutural do capital social trata dos aspectos estruturais dos relacionamentos entre os atores da rede e pode ser analisada a partir de dois diferentes ângulos: o aspecto da configuração da network $e$ a perspectiva dos laços da network (NAHAPIET; GHOSHAL, 1998). A apreciação da dimensão estrutural, quando se analisa a configuração da network, se faz pela determinação do modelo de ligações entre os seus participantes. Pode-se destacar como exemplo, a conectividade entre os membros das redes existentes em clusters de empresas que é usualmente constituída através de relações interpessoais informais (INKPEN; TSANG, 2005).

É possível realizar uma avaliação básica da estrutura de uma rede social mediante a análise da densidade e da centralidade desta rede, que já foram conceituados anteriormente. A densidade significa o número de ligações existentes com relação ao número de ligações 
possíveis (SCOTT, 2000). A centralidade é a medida de quão acessível um determinado ator está para os demais atores da rede e depende do padrão de distribuição, ou da maneira como os diversos atores estão interligados. A centralidade, além de medir a acessibilidade de um indivíduo, mede o número de caminhos de comunicação que passam por ela (MARINHODA-SILVA, 2003).

O conceito de laços da network diz respeito às maneiras como os atores estão relacionados entre si, especificamente com relação à proximidade do relacionamento (RÉGIS, 2005). Granovetter (1985) traz uma contribuição importante ao considerar que nem sempre as redes sociais detentoras de ligações fortes entre seus membros são as mais adequadas. $\mathrm{O}$ autor qualifica dois tipos ligações: os "laços fracos" e os "laços fortes”. Laços fortes são aqueles que se caracterizam pela intimidade, pela proximidade e pela intencionalidade em criar e manter uma conexão entre duas pessoas. Os laços fracos, por outro lado, caracterizam- se por relações esparsas, que não traduzem proximidade e intimidade.

Laços fortes constituem-se em vias mais amplas e concretas para as trocas sociais (WELLMAN apud RECUERO, 2005), enquanto os laços fracos possuem trocas mais difusas. O primeiro envolve uma elevada dose de tempo e um esforço maior dedicado à relação, existindo aspectos como a reciprocidade, a feição emocional e a confiança. Já os laços fracos envolvem transações pontuais em que não há tanta preocupação com a reciprocidade e a confiança, porém, servem como "pontes” para aumentar o fluxo e a abrangência de informações numa rede de relacionamentos mais ampla (GRANOVETTER, 1985).

\section{METODOLOGIA}

Os procedimentos metodológicos que foram utilizados na investigação do problema estudado se iniciaram com o processo de revisão de literatura, partindo-se de esforços para se entender melhor as relações dos conteúdos sobre o tema descrito pelos diversos pesquisadores.

Quanto à estratégia de pesquisa, é adotado o estudo de caso. É um método adotado para explicar os fenômenos ou problemas que apresentam características peculiares, alguma idiossincrasia com destaque que justifique o esforço da pesquisa (GONÇALVES; MEIRELLES, 2004).

O estudo em questão abrangeu uma amostra de 25 associados da ASCAP, caracterizada como amostra por acessibilidade. A coleta foi realizada nos períodos de outubro e novembro de 2008, na própria associação, em meio a reuniões realizadas semanalmente (autorizada pela diretoria da associação). A escolha da ASCAP está baseada no fato de haver grande expansão e desenvolvimento da região na qual está inserida a associação, existindo poucos estudos sobre o cenário. Além disso, foi uma das primeiras associações de confeccionistas do pólo de confecções. Esta associação também é uma das mais atuantes, promovendo cursos, feiras e exposições de negócios.

Os instrumentos de pesquisa são divididos da seguinte maneira: foi utilizado um cartão denominado cartão gerador de nomes (RÉGIS, 2005), em que os associados escreveram os nomes de seis pessoas que consideram as mais importantes da sua rede de relações dentro da 
ASCAP e o papel social delas. Em seguida, um questionário foi aplicado aos participantes do grupo de estudo, visando identificar a estruturação da rede e examinar a força dos laços existentes. O questionário empregado utilizou escala do tipo Likert de acordo com o instrumento utilizado por Régis (2005).

As respostas ao cartão gerador de nomes foram lançadas no software de análise de redes sociais UCINET 6.0 e NetDraw 2.0. Estes softwares foram utilizados para a confecção dos grafos. As respostas foram organizadas no software Microsoft Office Excel ${ }^{\mathrm{TM}}$, que auxiliou na digitação e classificação inicial. Posteriormente foram lançadas no software Ucinet 6.0 (2002) e exportadas para o software Netdraw 2.0 (2002).

Granovetter (1985) considera os laços forte como sendo aqueles caracterizados pela intimidade, proximidade e intencionalidade em criar e manter uma conexão entre duas pessoas. Os laços fracos não serão considerados, pois caracterizam relações frágeis que não fornecem durabilidade às relações. Para fim de identificar os laços muito fortes, o questionário apresentou cinco questões em busca da identificação da força dos laços. As perguntas diziam respeito ao tempo que a pessoa faz parte da rede de relações; o nível de equivalência da idade da pessoa com relação à idade do respondente; a freqüência de interação com a pessoa; a freqüência com que o negócio requer interação com essa pessoa e o nível de relacionamento com essa pessoa. Os seguintes critérios foram utilizados para classificar a força dos laços:

Granovetter (1973) afirma que o tempo de interação deve ser maior do que um ano entre os atores para que possa considerar laço forte. Desta maneira, os indivíduos que citaram que conhecem outros há menos de um ano foram excluídos da classificação de laço forte e muito forte. A diferença de idade maior em 10 anos ou menor que 10 anos indica diferença de gerações, tendendo a hábitos, costumes e comportamentos diferentes. Diferença de idade maior que 10 anos indica laço fraco (GRANOVETTER, 1973). A freqüência de interações com essa pessoa deve ser maior do que a necessidade imposta pelas atividades profissionais para se considerar laço forte (GRANOVETTER, 1973). Baixa interação indica laço fraco.

Por último, usou-se o critério de percepção do próprio indivíduo, e que eles indicaram o nível de relacionamento com a pessoa: distante, não tão próximo, próximo e muito próximo. Assim, os que consideraram distantes e não tão próximos foram excluídos deste critério.

\section{RESULTADOS E DISCUSSÕES}

Com a intenção de averiguar as redes sociais entre os membros da associação dos confeccionistas de Santa Cruz do Capibaribe - ASCAP, apresentam-se a seguir os resultados encontrados para identificação da estrutura da rede. Neste momento, são apresentados os dados dos participantes da pesquisa, especificamente dos associados da ASCAP.

Tabela 1: Dados dos participantes da pesquisa

\begin{tabular}{|c|c|c|c|}
\hline \multicolumn{4}{|c|}{ Idade dos Participantes } \\
\hline Entre 18 e 25 anos & Entre 26 e 35 anos & Entre 36 e 45 anos & Entre 46 e 60 anos \\
\hline $8 \%$ & $36 \%$ & $48 \%$ & $8 \%$ \\
\hline \multicolumn{3}{|c|}{ Escolaridade dos participantes } \\
\hline
\end{tabular}




\begin{tabular}{|c|c|c|c|c|c|c|c|}
\hline \multicolumn{2}{|c|}{$\begin{array}{l}\text { Ensino fundamental } \\
\text { completo }\end{array}$} & \multicolumn{2}{|c|}{$\begin{array}{c}\text { Ensino médio } \\
\text { incompleto }\end{array}$} & \multicolumn{2}{|c|}{$\begin{array}{l}\text { Ensino médio } \\
\text { completo }\end{array}$} & \multicolumn{2}{|c|}{ Superior incompleto } \\
\hline \multicolumn{2}{|c|}{$8 \%$} & \multicolumn{2}{|c|}{$4 \%$} & \multicolumn{2}{|c|}{$67 \%$} & \multicolumn{2}{|r|}{$21 \%$} \\
\hline \multicolumn{8}{|c|}{ Tempo de associação à ASCAP } \\
\hline Menos de 1 ano & \multicolumn{2}{|c|}{ Entre 1 e 4 anos } & \multicolumn{2}{|c|}{ Entre 4 e 8 anos } & \multicolumn{2}{|c|}{ Entre 8 e 12 anos } & Mais de 12 anos \\
\hline $8 \%$ & \multicolumn{2}{|c|}{$8 \%$} & \multicolumn{2}{|c|}{$48 \%$} & \multicolumn{2}{|c|}{$28 \%$} & $8 \%$ \\
\hline \multicolumn{8}{|c|}{ Participação na rede da associação na percepção dos pesquisados } \\
\hline \multicolumn{2}{|c|}{ Muito Ativo } & \multicolumn{2}{|c|}{ Ativo } & \multicolumn{2}{|c|}{ Não tão ativo } & \multicolumn{2}{|c|}{ Distante } \\
\hline \multicolumn{2}{|l|}{$16 \%$} & \multicolumn{2}{|c|}{$56 \%$} & \multicolumn{2}{|c|}{$20 \%$} & \multicolumn{2}{|r|}{$8 \%$} \\
\hline
\end{tabular}

Fonte: Dados do estudo

Considerando os papéis das pessoas citadas pelos associados no cartão gerador de nomes, constatou-se que os associados possuem em suas redes de relacionamentos, pessoas que não fazem parte da ASCAP. Os associados citaram o papel social desempenhado por cada pessoa de suas networks.

Do total dos resultados, foram em sua maioria amigos, 51\%, enfatizando a importância da rede de relacionamento de amizades na geração de benefícios para o indivíduo e da força dos laços fortes.

Cada indivíduo citado assume um ou mais papéis: sócio, amigo, consultor, irmão, empresário, etc. Através de cada papel, o indivíduo entra em contato com grupos particulares de pessoas que compartilham a mesma atividade ou interesse.

Com relação à configuração da network dos respondentes, a Figura (2) apresenta graficamente a estrutura da rede da associação dos confeccionistas de Santa Cruz do Capibaribe. Os associados (respondentes) estão representados no gráfico por um triângulo e pela cor vermelha, e as pessoas citadas pelos respondentes são representadas pela forma de um círculo e pela cor azul. Alguns destes círculos em azul são associados, porém, não participaram como respondentes, ou seja, as pessoas citadas pelos respondentes podem, ou não, ser associados da ASCAP. Esta representação é utilizada como base durante toda a apresentação dos resultados.

A Figura (2) faz destaque para os integrantes números 7, 12 e 22, representados por um triângulo maior, pois são os indivíduos que apresentam maior centralidade de entrada, ou seja, foram os indivíduos mais citados pelos respondentes. $\mathrm{O}$ ator 7 desempenha a função de presidente da ASCAP, sendo este citado por 12 dos associados. O ator 22 também faz parte da diretoria da associação, tendo sido citado por 14 integrantes. E finalmente, o ator 12, com maior número de citações (15 citações), sendo este o vice-presidente da ASCAP.

Esta mesma figura também apresenta destaque para os membros da diretoria (destacados com um círculo verde). Quanto à centralidade de grau de entrada, que representa o número de ligações que um ator recebe de outros atores, a Figura (2) mostra que os atores destacados na cor laranja (7, 12 e 22) foram os que obtiveram a maior indicação nas relações. Estes diretores, além de já ocuparem papéis centrais dentro da network, podem possuir maior facilidade para a troca de informações, maiores conhecimentos, apoio em momento de dificuldade e processos de mudança. Isto corrobora os achados de Soares (2008). 


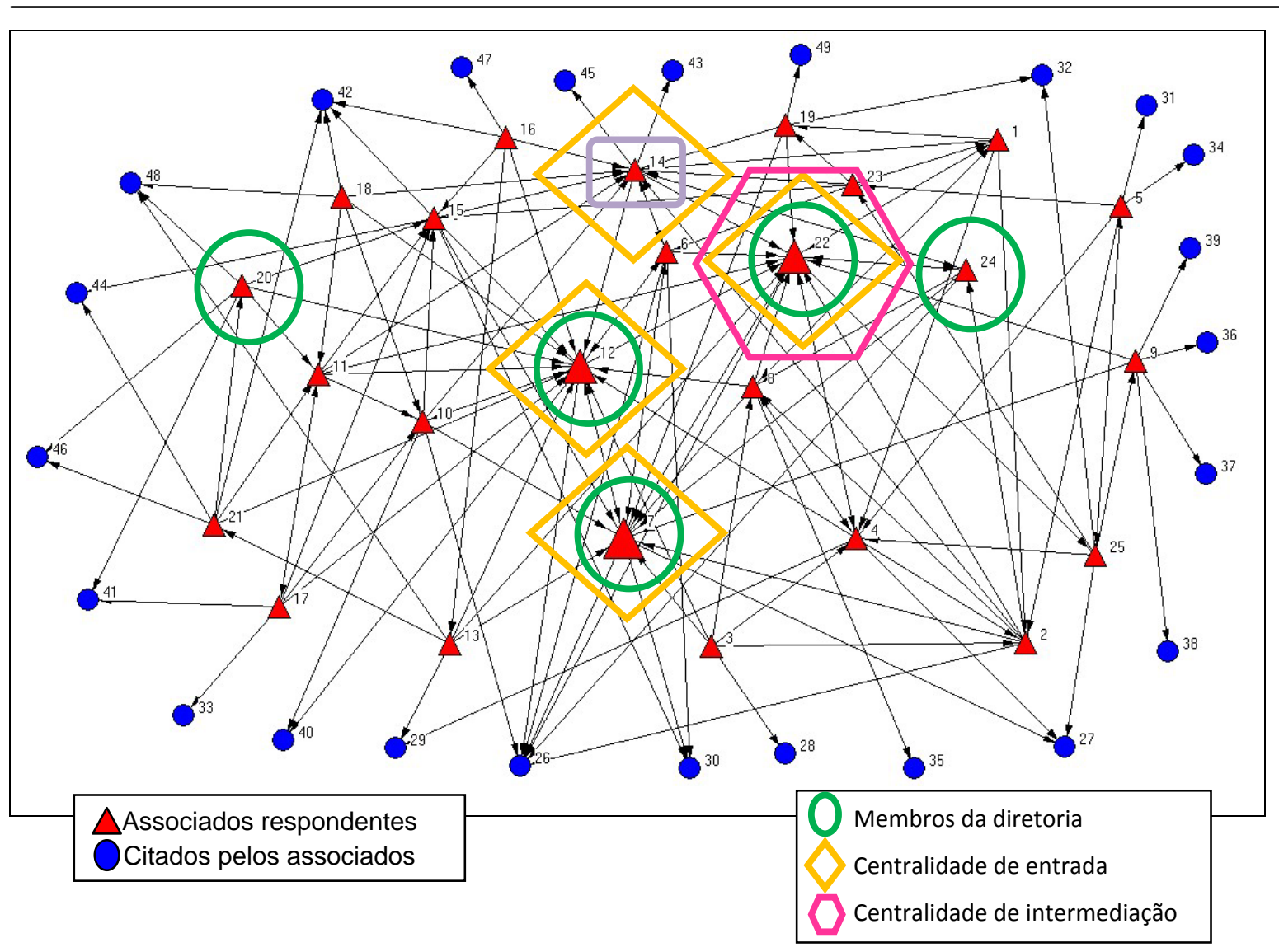

Figura (2): Network com todos os respondentes e pessoas por ele citadas com destaque nos integrantes Fonte: Dados do estudo

Das pessoas que não fazem parte da diretoria da ASCAP, e que foram citadas na pesquisa, podendo ou não ser associados, merece destaque o ator 14, tendo sido citado por 10 pessoas, obtendo assim um bom nível de centralidade de entrada, destacado na Figura 1 pela linha lilás. Quanto à centralidade de saída, não houve distinção entre os atores, uma vez que todos os respondentes, com exceção de apenas um, citaram seis pessoas no cartão gerador de nomes. Desta forma, a centralidade de saída é igual a seis para 24 dos respondentes.

$\mathrm{O}$ ator destacado na cor rosa representa a centralidade de intermediação. Significa que ele oferece acesso a outras pessoas da rede. De acordo com Marinho-da-Silva (2003), a centralidade de intermediação indica o poder praticado por um ator sobre as interações entre dois outros atores na rede, bem como representa o indivíduo que desempenha a função chamada de ponte na transferência de recursos. A centralidade de intermediação considera um ator como elemento central para alcançar outros atores, segundo Hanneman (2001). Neste caso especificamente, o ator 22 é o elemento central, pois exerce um respeitável papel intermediando informações.

Com relação à densidade da rede, o software Ucinet apresentou uma interligação entre os integrantes de 6,25\%. A densidade de uma rede social é o quociente das ligações efetivamente existentes entre os atores da rede pelo total de ligações possíveis entre estes atores (WASSERMAN; FAUST, 1994). Este valor da densidade, apesar de ser baixo, é 
comum entre as redes sociais. Valores mais altos, somente são alcançados em redes muito pequenas ou mesmo em cliques.

Os resultados da força dos laços serão apresentados em dois momentos: o primeiro momento considera os laços muito fortes, e o segundo momento considera os laços fortes, mas com menor intensidade do que os primeiros.

A Figura (3) apresenta a network, destacando os atores que obtiveram laços muito fortes. Um fator relevante a ser citado refere-se ao fato de que nenhuma das relações de laços muito fortes serem recíprocas, ou seja, a rede de laços muito fortes não apresenta nenhum clique.

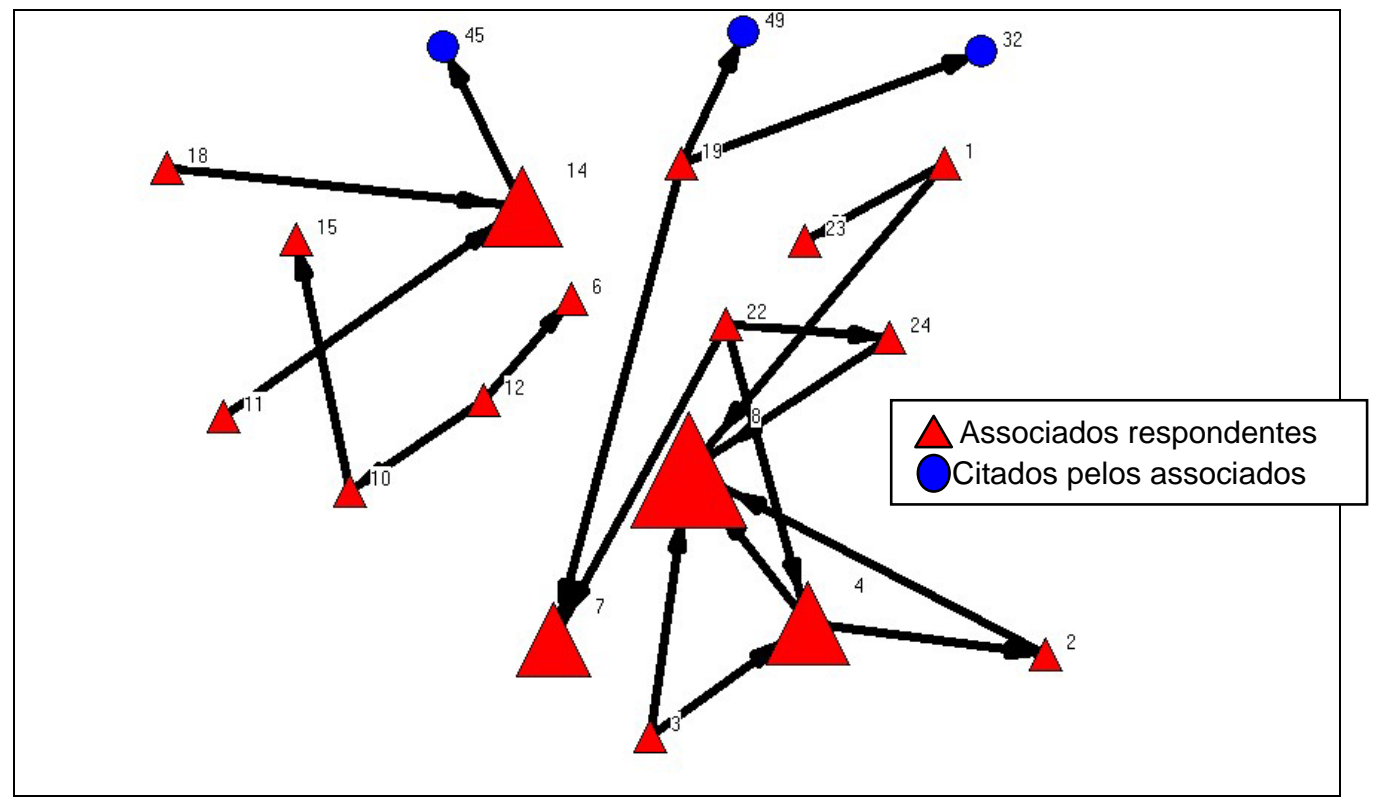

Figura 3: Network dos laços muitos fortes

Fonte: Dados do estudo

A Figura (4) apresenta a network dos laços fortes, destacando os atores que obtiveram mais laços fortes. Na rede de laços fortes, percebe-se que há reciprocidade entre os integrantes, apresentados pelas setas bidirecionais. A reciprocidade nas relações promove a troca de experiências e o apoio mútuo. Isso demonstra o grau em que há, nos relacionamentos da rede, grupos fechados, as chamadas "panelinhas" entre os respondentes. A elipse verde destaca um clique formado por 3 atores. 


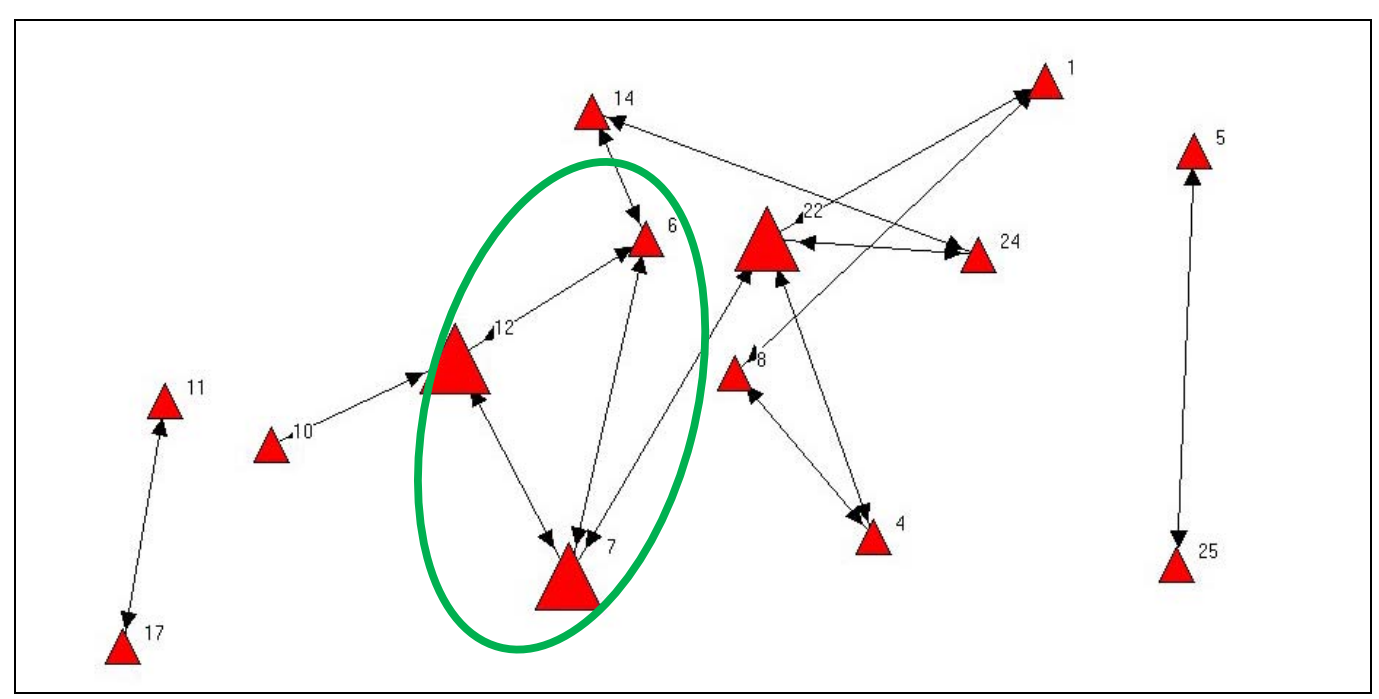

Figura 4: Network da reciprocidade entre os integrantes Fonte: Dados do estudo

\section{CONSIDERAÇÕES FINAIS}

Os novos modelos e arranjos organizacionais emergentes no contexto organizacional, baseados na interação e no compartilhamento de valores, vêm sendo pesquisados a cada dia mais. Diante desse contexto, o conceito de capital social é percebido com grande utilidade, particularmente na visão associada às redes. A utilização do capital social, especificamente na área das redes organizacionais e dentro de arranjos produtivos locais, abre vastas e significantes perspectivas de investigação na área, na compreensão do contexto das redes sociais, do capital social e dos APLs.

A ASCAP é uma instituição que visa representar os interesses dos confeccionistas e contribuir, através da prestação de serviços e parcerias, para o desenvolvimento sócioeconômico das empresas e do município. Percebe-se que, de acordo com os resultados encontrados, esta pode ser beneficiada e/ou prejudicada caso não reconheça a importância que as redes têm dentro do processo de desenvolvimento das empresas associadas, bem como da maneira como o capital social pode ser construído e desenvolvido para o benefício do grupo.

Fica evidente na análise dos papéis sociais que os laços de amizade são preponderantes. Através destes laços forma-se uma rede, de certa forma fechada e redundante, em que há troca de informações apenas entre os associados respondentes e os demais empresários do APL. Esse fato corrobora a missão da associação, que busca trocar experiências e gerar desenvolvimento para seus membros, uma vez que os indivíduos por si só não poderiam alcançar. As relações de informação podem contribuir para o desempenho do grupo, tornando os associados da ASCAP ainda mais competitivos (MARTELETO, 2004). Para Julien (apud BORGES JR., 2004), as redes informacionais desempenham um papel importante na dinâmica de aprendizagem e inovação das pequenas e médias empresas.

Os resultados apontam para os diretores da instituição como os principais atores da rede, devendo estes, já que exercem o papel de líderes formais da associação, aproveitar ao máximo os recursos e a posição de centralidade que a rede lhes confere, disseminando 
informações e servindo de elos para com os demais atores. Esses elos são muito úteis, pois podem oferecer aos associados da ASCAP vantagens competitivas com relação aos demais empresários da região, por meio de troca de informação, melhor poder de barganha, vantagens sobre informações fiscais e tributárias conseguidas com o governo e o apoio das diversas instituições que os rodeiam, por meio de parcerias e alianças. Não significa que os demais empresários do APL não possuam a devida importância, porém os membros da ASCAP, particularmente os que estão diretamente ligados à diretoria têm maiores condições de adquirir benefícios. Como normalmente acontece, após um período de tempo, as informações passam a circular pela periferia da rede, expandindo os benefícios a todos aqueles que estão ativamente conectados.

Os relacionamentos se mostram bem estruturados, com laços fortes bem concretizados dentro da rede da ASCAP. Os empresários que conseguirem perceber a importância da rede, visualizar seus laços e saber melhor utilizar o capital social disponível na associação, poderão obter vantagens no crescimento dos seus negócios, uma vez que elas proporcionam acesso a conhecimentos e a recursos que, de outra maneira não estariam disponíveis.

O processo de surgimento, desenvolvimento e consolidação de um APL levam a posição privilegiada no mercado. Contudo, como todo processo evolutivo, chega-se à etapa inversa, ou seja, o desmantelamento da rede, devido à competição com outros APLs do mesmo ramo de negócios (ZACCARELLI et al, 2008). Isto mostra a necessidade de certos cuidados pelos empresários do APL. No caso da rede de confeccionistas da ASCAP, foi constatado um grande número de laços fortes e com poucas ligações externas, o que deixa a rede muito voltada para si mesma e pouco conectada com APLs de outras regiões. De acordo com Granovetter (1973), são os laços fracos que propiciam a entrada de informações novas que podem contribuir para que o APL de Santa Cruz do Capibaribe se mantenha atualizado através de suas ligações (pontes) externas.

Diante do apresentado no decorrer deste trabalho, chega-se à conclusão de que há construção de capital social no APL de Santa Cruz do Capibaribe, promovido pela associação dos confeccionistas. Esta ação coletiva pode elevar o desempenho das instituições, tornandoas mais ágeis e desenvolvidas. Entretanto, é importante citar que o "capital social não é a chave para o sucesso organizacional” (COHEN; PRUSAK, 2001, p. 11). Este deve ser bem aproveitado, e retirado os benefícios que podem ser adquiridos com sua utilização.

\section{REFERÊNCIAS}

AQUINO, Jakson Alves de. As teorias da ação social de Coleman e de Bourdieu. Humanidades e Ciências Sociais. v. 2 n. 2, 2000.

BORGATTI, S.P. NetDraw: Graph Visualization Software. Harvard: Analytic Technologies, 2002.

BORGATTI, S.P., EVERETT, M.G.; FREEMAN, L.C.. Ucinet for Windows: Software for Social Network Analysis. Harvard, MA: Analytic Technologies, 2002. 
BORGES JR., Cândido Vieira. Características e Contribuições das Redes para o Desenvolvimento das Pequenas e Médias Empresas. Em: Anais $\mathbf{2 8}^{\circ}$ Encontro da Associação Nacional de Pós- Graduação em Administração, Curitiba-PR, 2004.

BOURDIEU, Pierre. The forms of capital. In: RICHARDSON, J. (comp.) Handbook of theory and research for the sociology of education. Nova York: Greenwood, 1986.

CLARK, Louise. Manual para el mapeo de redes como una herramienta de diagnóstico. Centro Internacional de Agricultura Tropical - CIAT. Bolivia, 2006, 31.p.

COHEN, Don; PRUSAK, Laurence. Good company: how social capital makes organizations work. Boston, Massachusetts: Harvard Business School Press, 2001.

COLEMAN, James Samuel. Foundations of social theory. Cambridge: Harvard University Press, 1990.

CROSS, Rob; PRUSAK, Laurence. The people who make organizations go - or stop. Harvard Business Review. Boston, EUA, 2002.

GALVÃO, Olímpio José de Arroxelas. ‘Clusters’ e distritos industriais: estudos de casos em países selecionados e implicações de política. Planejamento e Políticas Públicas. Brasília: 2000.

GÓMES, Daniel et al. Centrality and power in social networks: a game theoric approach. Mathematical Social Sciences, v.46, p.27-54, 2003.

GRANOVETTER, Mark. The strength of weak ties. American Journal of Sociology. v. 91, n. 3, p. 1369-1380, nov./1985.

HANNEMAN, Robert A. Introduction to social network methods. 2001. Disponível em: $<$ http://www.faculty.ucr.edu/ hanneman/nettext/>. Acesso em 04 set. 2008.

INKPEN, A. C.; TSANG, E. W. K. Social capital, networks, and Knowledge transfer. Academy of Management Review. Vol. 30, No. 1, 146-165, 2005.

KAY, Alan; PEARCE, John. Social Capital. Information Paper. CBS Network Services Limited: Edinburgh, 2003.

MARINHO-DA-SILVA Marcus C. Redes sociais intraorganizacionais informais e gestão: um estudo nas áreas de manutenção e operação da planta HYCO-8, Camaçari, BA. Dissertação (Mestrado) - Universidade Federal da Bahia. Escola de Administração. NPGA. Salvador-BA 2003.

MARQUES, Eduardo César. Redes sociais e instituições na construção do Estado e da sua permeabilidade. Revista Brasileira de Ciências Sociais, v. 14, n. 41, p. 45-67, out/1999.

MARTELETO, Regina Maria. Análise de redes sociais - aplicação nos estudos de transferência da informação. Ci. Inf., Brasília, v. 30, n. 1, p. 71 - 81, jan./abr. 2001.

Análise de redes sociais - aplicação nos estudos de transferência da informação. RITS Organizações em Rede. Tema do mês de março, 2005.

MARTELETO, Regina Maria; SILVA, Antonio Braz de Oliveira e. Redes e capital social: o enfoque da informação para o desenvolvimento local. Ci. Inf., Brasília, v. 33, n. 3, p. 41 - 49, set./dez. 2004. 
NAHAPIET, J.; GHOSHAL, S. Social capital, intellectual capital, and the organizational advantage. Academy of management review. 23: 242-266. 1998.

PUTNAM, Robert D. Comunidade e democracia: a experiência da Itália moderna. Trad. Luiz Alberto Monjardim. 2. ed. Rio de Janeiro: FGV, 2000.

. Tuning in, tuning out: The strange disappearance of social capital in America. The 1995 Ithiel de Sola Pool Lecture. Political Science and Politics, p. 664-683, 2005.

RECUERO, Raquel da Cunha. Um estudo do capital social gerado a partir de redes sociais no orkut e nos weblogs. Revista FAMECOS, Porto Alegre, nº 28, dez/2005.

REGIS, H. P. Construção social de uma rede informal de mentoria nas incubadoras de base tecnológica do Recife. Tese (Doutorado) - Universidade Federal e Pernambuco. Programa de Pós Graduação em Administração. PROPAD. Recife-PE, 2005.

RÉGIS, H. P.; DIAS, Sônia M. R. C; BASTOS, A. V. B. Articulando Cognição, Redes e Capital Social: um estudo entre empresários participantes de incubadoras de empresas. Em: Anais $\mathbf{3 0}^{\circ}$ Encontro da Associação Nacional de Pós-Graduação e Pesquisa em Administração, Salvador-BA, 2006.

RIGO, Ariádne Scalfoni; OLIVEIRA, Rezilda Rodrigues. Análise de Redes Sociais e Existência de Capital Social em um Projeto de Desenvolvimento Local. VI conferencia regional de istr para américa latina y el caribe. 8 al 11 noviembre de 2007, Salvador de Bahía, Brasil. Organizan: ISTR y CIAGS/UFBA.

Frustração de expectativas e (des)construção do capital social: o caso da comunidade Caranguelo Tabaiares da Cidade do Recife. XXXI Encontro da ANPAD. 22 a 26 de setembro de 2007, Rio de Janeiro.

Capital social, desenvolvimento local e stakeholders: o caso do projeto Urbe do Sebrae. Cadernos Ebape. v. 6, n. 2. Jun. 2008.

SCOTT, John. Social network analysis: a handbook. 2. ed. London: Thousands Oaks, California: Sage Publications, 2000.

SEBRAE (Serviço Brasileiro de Apoio às Micro e Pequenas Empresas). Estudo de caracterização econômica do Pólo de Confecções do Agreste Pernambucano. Maio de 2003.

Arranjos Produtivos Locais. Disponível em: <http://www.sebrae.org.br/br/ cooperecrescer/arranjosprodutivoslocais.asp>. Acesso em: 30 de agosto 2008.

SOARES, Norberto Lucas. O papel da Network para o Desenvolvimento da Carreira: a percepção dos gerentes da Gilbarco do Brasil S/A. Dissertação (Mestrado) - Faculdade Boa Viagem. Mestrado Profissional em Gestão Empresarial. Recife-PE, 2008.

ZACCARELLI, Sergio Baptista et al. Clusters e redes de negócios: uma nova visão para a gestão dos negócios. São Paulo: Atlas, 2008.

WASSERMAN, Stanley; FAUST, Katherine. Social network analysis: methods and applications. Cambridge, New York: Cambridge University Press, 1994. 